\title{
ESTUDO DA INTERFACE DAS ESTRUTURAS DE CONCRETO ENTRE VIGAS/LAJES E ALVENARIA DE BLOCO CERAMICOS
}

\author{
FRIEDERICH DOS SANTOS, MARCUS DANIEL DOS SANTOS TATIM FILHO, YURI \\ Prof. MSc Engenheiro Civil \\ Universidade de Santa Cruz do Sul \\ RS/Brasil \\ marcusds@unisc.br \\ Acadêmico de Engenharia Civil \\ Universidade de Santa Cruz do Sul \\ RS/Brasil \\ yuritatim@icloud.com
}

\section{RESUMO}

A etapa da fixação da alvenaria de vedação na estrutura de concreto armado, ou encunhamento, está relacionada com muitas causas patológicas. A NBR 8545:1984, normativa para execução de alvenaria sem função estrutural, contém procedimentos antigos à execução atual, como ao encunhamento. Autores elaboraram métodos de como executar a fixação. A metodologia foi elaborada com ensaios de argamassas comercializadas para o uso e execução da fixação, concluindo o melhor desempenho segundo propostas de autores. Foi realizada a análise dos resultados de ensaios das resistências de tração na flexão, compressão e modulo de elasticidade das argamassas para encunhamento, que segundo autores devem ter baixas resistências e módulo de elasticidade a fim de suportar as deformações das vigas imposta sobre a parede, resultados satisfatórios em duas das argamassas ensaiadas. Para evitar manifestações patológicas faz-se necessário parâmetros para execução e escolha do tipo de material para o encunhamento.

Palavras-chave: patologia, argamassas, encunhamento, modulo de elasticidade, resistencias.

\section{ABSTRACT}

The step of fixing the sealing masonry to the reinforced concrete structure, or wedging, is related to many pathological causes. The NBR 8545: 1984, regulation for masonry execution without structural function, contains procedures old to the current execution, such as wedging. Authors have devised methods on how to perform fixation. The methodology was elaborated with mortar tests commercialized for the use and execution of the fixation, concluding the best performance according to the authors proposals. It was performed the analysis of the test results of tensile strengths in flexion, compression and modulus of elasticity of wedging mortars. satisfactory in two of the mortars tested. To avoid pathological manifestations, it is necessary parameters for execution and choice of material type for wedging.

Keywords: pathology, mortars, wedging, elastic modulus, resistances

\section{INTRODUÇÃO}

Para Franco (2004), os fatores que explicam o porquê de as patologias não se manifestarem antes se relacionam diretamente com os desenvolvimentos tecnológicos de outras etapas da construção.

Umas das etapas de muita importância, que é relacionada com muitas causas patológicas contemporâneas, é a chamada fixação da alvenaria de vedação na estrutura de concreto armado, ou encunhamento, como é geralmente conhecida. O processo é basicamente, o preenchimento de um espaço deixado propositalmente entre a alvenaria de vedação e a estrutura de concreto armado com material deformável e que suporte as deformações impostas da estrutura na parede.

Em estudos passados, elaborados por autores de renome na área da construção civil, obteve-se uma gama de conceitos e conhecimentos na tentativa de aprimoramento dos processos executivos da NBR 8545:1984, norma brasileira vigente, a qual explica sobre a execução de alvenaria sem função estrutural, e contém procedimentos antigos, de processos de execução, porem, atualmente, já existem novos estudos em como proceder a execução da alvenaria de vedação, 
principalmente sobre os melhores procedimentos da interação das interfaces entre blocos cerâmicos e estruturas de concreto armado.

\section{REVISÃO BIBLIOGRÁFICA}

O aprimoramento da execução das estruturas e vedações levou à alterações significativas no processo de encunhamento das alvenarias. $O$ processo consistia em preencher a última camada entre a parede e a laje, ou viga do pavimento superior, com pedaços de bloco cerâmico ou de concreto. Os fragmentos atuavam como uma cunha no espaço do encunhamento. A justificativa para este processo era para que a parede não se movimentasse entre os pilares, porem em registro de casos ocasionados pela pressão da deformação lenta da estrutura levava ao aparecimento de trincas e/ou rompimento de alvenarias, e revestimentos. $\mathrm{O}$ uso de concretos mais resistentes associado à introdução de ferramentas tecnológicas proporcionaram maior precisão ao projeto, portanto vigas e pilares passaram a atuar com tensões mais elevadas e tornaram-se mais flexíveis, logo passando a transferir mais cargas para a alvenaria (FRANCO, 2004).

As recomendações da NBR 8545:1984 em obras de concreto armado, são de que alvenaria de vedação deve ser interrompida logo abaixo das vigas e lajes. Esse espaço deve ser preenchido logo após 7 dias, de forma que a alvenaria e a estrutura sejam perfeitamente travadas. Em obras com mais de um pavimento, só deve ser executada a fixação, respeitado o prazo de 7 dias, quando o pavimento logo acima esteja com a alvenaria elevada até igual altura.

Segundo a NBR 13281:2005, argamassa de encunhamento é indicada para o fechamento da alvenaria de vedação após a última fiada de blocos assentados.

Existem diversos produtos no mercado, cada um com suas características e indicações. O que mais é indicado no processo de encunhamento, segundo autores, são argamassas especificas, com propriedades que suportem as deformações, ou espuma de poliuretano.

Nos casos de alvenaria de vedação em que a mesma está envolta de uma estrutura deformável e não deve ser utilizada como travamento da estrutura, uma vez que a alvenaria é "apertada" sofre de antemão uma deformação razoável na sua estrutura, levando a estados de tensões os quais a alvenaria não suporte. Para execução da fixação, é recomendada material com elevada capacidade de absorver deformações (SANTOS JUNIOR, 2014 apud SABBATINI, BRITO e SELMO, 1988).

Deve-se deixar um espaço para o encunhamento flexível com o uso de argamassa de menor resistência, ou de outros materiais que apresentem grande capacidade de acomodar deformações, como por exemplo, a espuma de poliuretano. $\mathrm{O}$ detalhamento desse tipo de interface em um projeto de alvenaria de vedação pode reduzir o índice de patologias das edificações contemporâneas prontas (SILVA et al, 2006).

Em estruturas muito deformáveis, paredes muito extensas ou enfraquecidas pela presença de aberturas, recomenda-se ligações o mais flexíveis possível, por exemplo, o uso de poliuretano expandido ou "massa podre" composta por esferas de EPS (poliuretano expandido). Os materiais e detalhes devem ser estudados para garantir a integridade do revestimento na parede. Cabe ao projetista definir se toda a espessura da parede será preenchida ou apenas dois cordões laterais de argamassa de encunhamento. As recomendações para a execução da fixação (THOMAZ, 2009):

> Não deve ser executada de forma alguma antes que a parede do pavimento superior esteja concluída;

$>$ Seja executada de cima para baixo com um prazo de 14 dias do final da elevação da alvenaria do último pavimento;

Espaçamento fique em torno de $1,5 \mathrm{~cm}$ a $3,0 \mathrm{~cm}$;

$>$ O material utilizado deve ser bem compactado no interior da junta para que não ocorra destacamentos;

> Não deve ser empregada o uso de argamassa rica em cimento ou com aditivos expansores.

No procedimento de fixação, deverá ser deixado um espaçamento de 2,0 a 3,0 cm entre a alvenaria e a estrutura de concreto, e proceder a execução com um material que tenha elevada capacidade de absorver deformações. Podendo ser aplicada espuma de poliuretano ou argamassa rica em cal e com baixo teor de cimento, de traço 1:3:12 (cimento:cal:areia, em volume) por exemplo. Sequência de execução da fixação da alvenaria de vedação (LORDSLEEM JUNIOR, 2000):

$>$ A limpeza e umedecimento do local de fixação com auxílio de uma broxa;

$>$ Fixar a alvenaria com a utilização de bisnaga; 
$>$ Em paredes de fachadas, pela face interna da mesma, é preenchida toda a junta até a metade da alvenaria;

$>$ Quando realizada a limpeza, taliscamento ou chapiscamento da fachada, executar o preenchimento do restante da junta;

$>$ Acabamento da junta com auxílio da colher de pedreiro;

$>$ Se o espaçamento deixado para fixação for maior que $3,5 \mathrm{~cm}$, a argamassa deverá ser colocada em duas camadas com intervalo de 24 horas entre elas;

$>$ Alvenaria já elevada há pelo menos 28 dias;

$>$ Fixação deve ser executada do pavimento superior para o inferior com prazo de $24 \mathrm{~h}$ entre os pavimentos.

Uma pré-classificação do tipo de encunhamento de paredes e então escolha do material adequado deve ser feita (DALDON, 2008 apud SABBATINI, 2002):

Tabela 01: Classificação dos tipos de encunhamento e respectivos materiais

\begin{tabular}{c|l}
\hline Encunhamento & Materiais \\
\hline \multirow{3}{*}{ Com pré-tensionamento (rígido) } & Tijolos inclinados a $45^{\circ}$ \\
\cline { 2 - 2 } & Cunhas de concreto \\
\cline { 2 - 2 } & Argamassa Expansiva \\
\hline Sem pré-tensionamento (resiliente) & Argamassa de baixo modulo de elasticidade \\
\hline Plástico & Espuma de poliuretano \\
\hline
\end{tabular}

\subsection{Deformação das estruturas de concreto: lajes e vigas}

Entende-se por flecha o maior deslocamento vertical da viga, e para o cálculo da mesma e sua rigidez é caracterizado pelo produto entre módulo de elasticidade secante do concreto e a inércia da seção de concreto (Ecs. Ic). Três estádios são caracterizados pelo comportamento da estrutura, Estádio I é quando a viga não fissura, Estádio II quando há fissuração na viga, Estádio III onde o aço começa a escoar. A viga só rompe quando as deformações da fibra mais comprimida do concreto ou mais tracionada da armadura atingem valores elevados, caracterizado pelo ELU, estado-limite último (FRANÇA, 2003).

Nas estruturas de concreto armado, o estado-limite ultimo de instabilidade é atingido, segundo a NBR 6118:2014, quando se eleva a intensidade do carregamento sobre a estrutura, logo suas deformações igualmente se elevam, e os elementos são submetidos a flexo-compressão em que o aumento da capacidade resistente passa a ser inferior ao aumento da solicitação.

A NBR 6118:2014 fornece dados de valores-limites de deslocamentos que visam proporcionar um adequado comportamento da estrutura em serviço, e para as paredes de vedação, não participantes do elemento estrutural, o tipo de classificação são os "efeitos em elementos não estruturais". Após a construção da parede, para as alvenarias, caixilhos e revestimentos, o deslocamento-limite é de 1/500 e 10mm e a rotação nos elementos que suportam a parede é de 0,0017 rad. O movimento lateral de edifícios provocado pela ação do vento para combinação frequente tem um deslocamentolimite de H/1700 e Hi/850, sendo $\mathrm{H}$, altura total do edifício, e Hi, desnível entre dois pavimentos vizinhos. Já os movimentos térmicos verticais e horizontais, provocados pelas diferenças de temperaturas, tem-se deslocamento-limite de $1 / 400$ e $15 \mathrm{~mm}$ para verticais em paredes, e para os horizontais $\mathrm{Hi} / 500 \mathrm{em}$ forros. Após a construção do forro o deslocamento-limite para revestimentos colocados é de 1/350, e para revestimentos pendurados ou com juntas é de 1/175.

\subsection{Patologias}

Tendo-se inúmeros problemas patológicos que afetam os edifícios, residências, comerciais ou institucionais, que acabam muitas vezes ligados a trincas, devido a aspectos fundamentais como: o aviso de um eventual estado perigoso para a estrutura, o comprometimento do desempenho da obra, e o constrangimento psicológico que a fissuração do edifício exerce sobre seus usuários. O recalque plástico da argamassa de assentamento cogitará abatimento da alvenaria. Em caso de a fixação da alvenaria de vedação ter sido executada de maneira precoce, ocorrerá o destacamento entre os componentes dos blocos cerâmicos e a estrutura de concreto, representado na figura 01 (THOMAZ et al, 2003). 


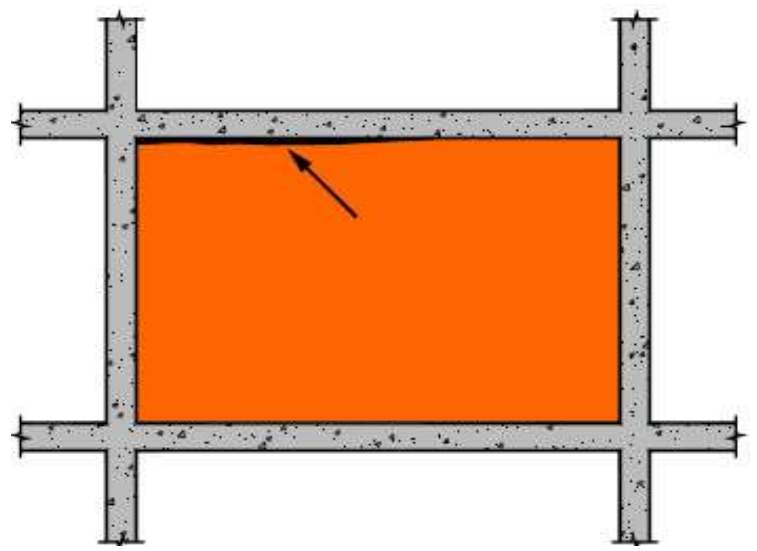

Figura 01: Destacamento provocado pela fixação precoce da alvenaria (Fonte: THOMAZ et al, 2003)

Por consequência das fissuras ocasionadas pela deformação da estrutura sobre a alvenaria de vedação, as figuras $02 \mathrm{a}$ e $02 \mathrm{~b}$ apresentam casos reais em edifícios contemporâneos, causando constrangimento psicológico para seus usuários, comprometendo o desempenho da obra, e até causando um estado perigoso ao descolar o revestimento das fachadas, como o exemplo representado na figura 03.

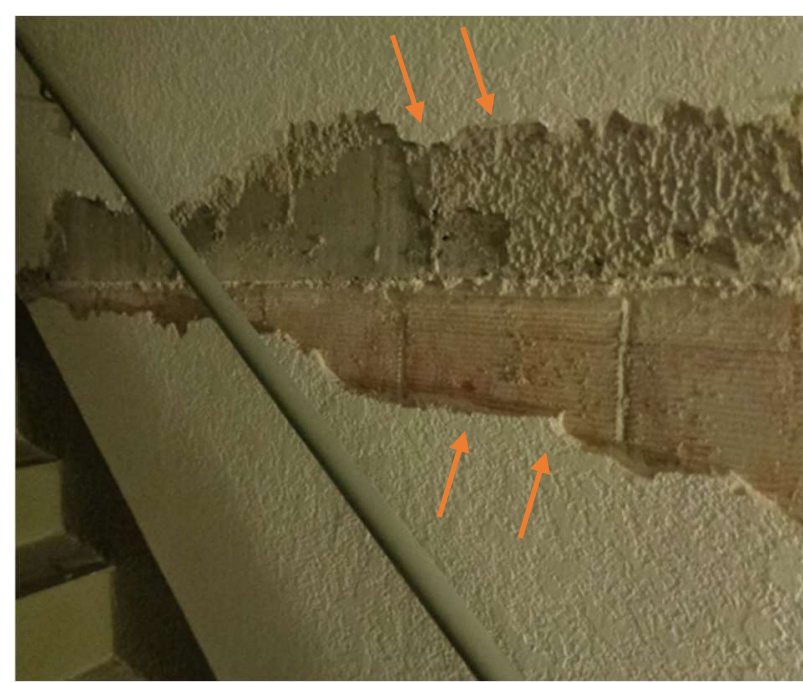

$02 \mathrm{a}$

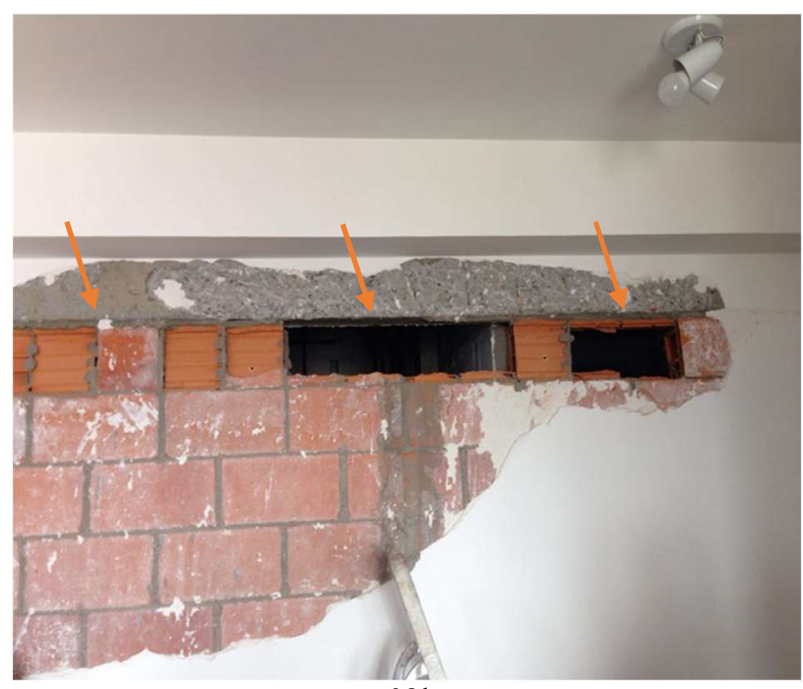

$02 \mathrm{~b}$

Figura 02: Patologia ocasionado na região do encunhamento na parte interna de edifício (Fonte: SANTOS, 2019)

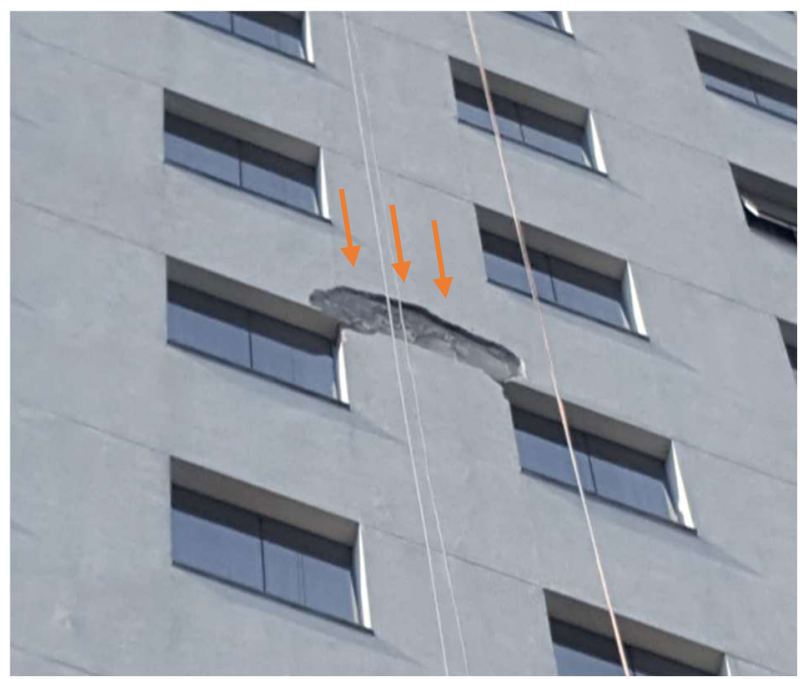

Figura 03: Patologia ocasionado na região do encunhamento na parte externa de edifício (Fonte: SANTOS, 2019) 


\section{METODOLOGIA}

O presente artigo foi proposto em referência à fixação da alvenaria de vedação na estrutura de concreto armado (encunhamento). Visto que existem no mercado diferentes argamassas de encunhamento com diferentes resistências, segundo suas fichas técnicas, realizou-se ensaios com quatro tipos de argamassas de encunhamento e duas argamassas de assentamento em traço 1:6 (cimento:areia) com aditivo expansor e sem aditivo, testando suas resistências à tração na flexão e compressão, concluindo quais tipos de argamassas são melhores ao serem empregadas na execução do encunhamento.

\subsection{Procedimentos}

Para o preparo das argamassas, seguiu-se os parâmetros propostos pela NBR 16541:2016, suficientes para que possam ser moldados seis corpos de prova de cada argamassa de encunhamento a serem ensaiadas, com tamanhos de 4 $\mathrm{cm} \times 4 \mathrm{~cm} \times 16 \mathrm{~cm}$, conforme NBR 13279:2005, em moldes prismáticos metálicos que consistem em armações abertas com paredes removíveis, formando três compartimentos necessários para moldar os corpos de prova, possibilitando realizar ensaios para determinar suas resistências a tração na flexão e à compressão, a partir das equações expostas na norma, e adensados na mesa de adensamento por queda. Ainda é estabelecido uma tolerância de tempo para a ruptura dos corpos de prova por idade. Os ensaios de resistência a tração na flexão e resistência a compressão das argamassas foram realizados com 28 dias, com uma tolerância de $8 \mathrm{~h}$, respeitando a norma. Após a cura de 28 dias, foram realizados os ensaios de densidade de massa aparente no estado endurecido, em $\mathrm{kg} / \mathrm{m}^{3}$, a partir da fórmula fornecida pela NBR 13280:2005, com os corpos de prova prismáticos $4 \times 4 \times 16 \mathrm{~cm}$.

Foram moldados corpos de prova cilíndricos 10x20 cm, conforme NBR 5738:2015, em adensamento manual, preenchida em 2 camadas de 12 golpes cada, para determinação do modulo de elasticidade das argamassas, utilizando o método conforme NBR 8522:2017, norma que estabelece os métodos de ensaio para determinação dos módulos estáticos de elasticidade e de deformação à compressão do concreto endurecido. Para determinação da deformação do corpo de prova foi fixado ao mesmo o extensômetro, com precisão de $0,0001 \mathrm{~mm}$.

\subsection{Materiais utilizados}

Diante da disponibilidade do mercado foram escolhidas 4 argamassas industrializadas e 1 aditivo expansor que segundo suas fichas técnicas, são classificados e compostos conforme tabela 02 :

Tabela 02: Descrição dos materiais utilizados (Fonte: Fichas técnicas)

\begin{tabular}{c|l}
\hline Argamassa & \multicolumn{1}{c}{ Descrição } \\
\hline ARG1 & $\begin{array}{l}\text { É uma argamassa de mistura seca composta por cimento, cal hidratada, agregados minerais calcários } \\
\text { e quartzoso com granulometria controlada, filer mineral e aditivos compensadores de retração. }\end{array}$ \\
\hline ARG2 & $\begin{array}{l}\text { É uma argamassa indicada para o assentamento de blocos de alvenaria de vedação e fixação (blocos } \\
\text { de concreto, cerâmicos e tijolos comuns). Não deve ser utilizada para outros serviços. }\end{array}$ \\
\hline ARG3 & $\begin{array}{l}\text { Argamassa expansiva com retração compensada, a base de cimento, agregados selecionados e } \\
\text { aditivos especiais. Objetivando evitar trincas localizadas na região de encontro entre vigas e } \\
\text { alvenarias. }\end{array}$ \\
\hline ARG4 & $\begin{array}{l}\text { Argamassa indicada para assentamento de blocos de alvenaria de vedação e fixação de alvenarias } \\
\text { (encunhamento). É uma mistura homogênea de cimento, cal hidratada, agregados minerais com } \\
\text { granulometria controlada e aditivos químicos. }\end{array}$ \\
\hline ARG1:6A & $\begin{array}{l}\text { Argamassa em traço 1:6 (cimento:areia), utilizado cimento CP IV 32 RS e areia média. } \\
\text { expansor para mistura em argamassas secas, que tem o objetivo de compensar a retração natural da } \\
\text { argamassa. }\end{array}$ \\
\hline
\end{tabular}


A relação dos materiais utilizados na mistura das argamassas é informada na tabela 03. Suas consistências foram determinadas com base na orientação da NBR 13276:2016, que sem a informação da quantidade de água necessária na mistura, deverá estar entre $260 \mathrm{~mm} \pm 5 \mathrm{~mm}$. Então todas as argamassas foram padronizadas com a consistência orientada na norma, independentemente da quantidade de água informada no saco do material das argamassas industrializadas.

Tabela 03: Relação de materiais utilizados na mistura das argamassas (Fonte: Autor)

\begin{tabular}{c|c|c|c|c|c}
\hline Argamassa & Argamassa (g) & Cimento (g) & $\begin{array}{c}\text { Agregado miúdo } \\
(\mathbf{g})\end{array}$ & $\begin{array}{c}\text { Aditivo } \\
\text { expansor (g) }\end{array}$ & Água (mL) \\
\hline ARG1 & 4000 & - & - & - & 527 \\
\hline ARG2 & 4000 & - & - & - & 587 \\
\hline ARG3 & 4000 & - & - & - & 569 \\
\hline ARG4 & 4000 & - & - & - & 586,5 \\
\hline ARG1:6 & - & 572 & 3432 & - & 594 \\
\hline ARG1:6A & - & 572 & 3432 & 5,72 & 450 \\
\hline
\end{tabular}

\section{RESULTADOS OBTIDOS}

A tabela 04 contém as médias dos resultados das densidades de massa aparente no estado endurecido, módulo de elasticidade, resistência à tração na flexão e resistência à compressão das argamassas ensaiadas, aos 28 dias de idade.

Tabela 04: Resultados médios das argamassas para encunhamento ensaiadas (Fonte: Autor)

\begin{tabular}{c|c|c|c|c}
\hline \multirow{2}{*}{ Argamassa } & \multicolumn{3}{|c}{ Resultados médios } \\
\cline { 2 - 5 } & $\begin{array}{c}\text { Densidade de massa } \\
\text { aparente no estado } \\
\text { endurecido }\left(\mathbf{k g} / \mathbf{m}^{3}\right)\end{array}$ & $\begin{array}{c}\text { Módulo de } \\
\text { elasticidade } \\
\text { (GPa) }\end{array}$ & $\begin{array}{c}\text { Resistência a tração } \\
\text { na flexão (MPa) }\end{array}$ & $\begin{array}{c}\text { Resistência a compressão } \\
\text { (MPa) }\end{array}$ \\
\hline ARG1 & 1539 & 2,5 & 0,7 & 1,2 \\
\hline ARG2 & 1453 & 4,8 & 1,1 & 1,7 \\
\hline ARG3 & 1456 & 8,8 & 2,4 & 4,4 \\
\hline ARG4 & 1935 & 8,0 & 1,4 & 4,0 \\
\hline ARG1:6 & 1855 & 11,2 & 1,4 & 5,2 \\
\hline ARG1:6A & 1853 & 16,5 & 2,9 & 10,1 \\
\hline
\end{tabular}

\subsection{Análise de resultados}

Para análise dos resultados, foi realizada a classificação das argamassas seguindo a NBR 13281:2005 e a biografia estudada por Daldon (2008), demonstrada na tabela 05.

Tabela 05: Classificação das argamassas para encunhamento ensaiadas (Fonte: Autor)

\begin{tabular}{c|c|c}
\hline \multirow{2}{*}{ Argamassa } & \multicolumn{2}{|c}{ Classificação } \\
\cline { 2 - 3 } & NBR 13281:2005 & Daldon (2008) \\
\hline ARG1 & P1;M4;R1 & Resiliente \\
\hline ARG2 & P2;M4;R2 & Resiliente \\
\hline ARG3 & P4;Mígido \\
\hline ARG4 & P4;M6;R3 & Rígido \\
\hline ARG1:6 & P5;M6;R3 & Rígido \\
\hline ARG1:6A & P6;M6;R5 & Rígido \\
\hline
\end{tabular}


Analisando os resultados das argamassas ARG1 e ARG2 com resistências de tração na flexão e compressão baixas, e módulos de elasticidades relativamente baixos, elas podem ser classificadas como materiais resilientes. Visto que as outras argamassas apresentaram módulos de elasticidades elevados em relação a ARG1 e ARG2, as classificações foram determinadas como materiais rígidos, seguindo a biografia estudada por Daldon (2008).

$\mathrm{MPa}$.

O gráfico 01 apresenta a relação dos resultados médios das resistências de tração na flexão e compressão, em

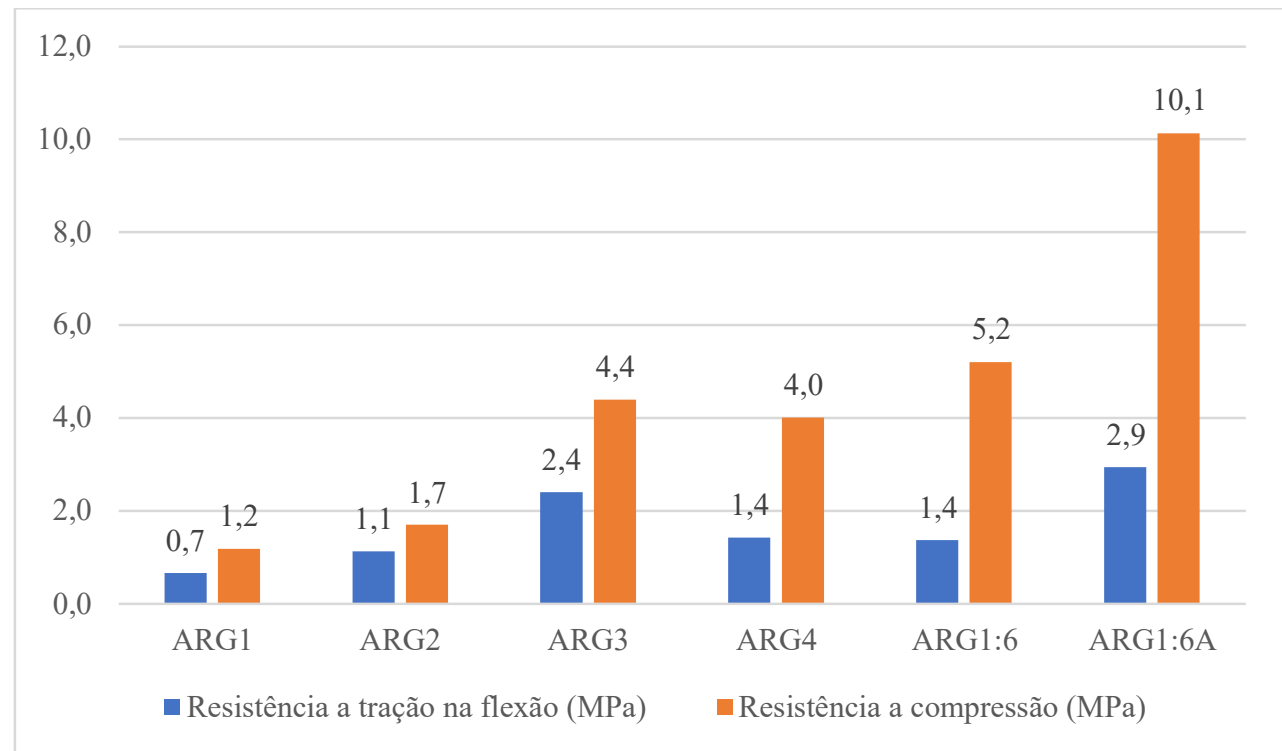

Gráfico 01: Médias das resistências à tração na flexão e compressão das argamassas ensaiadas (Fonte: Autor)

A relação dos resultados médios dos módulos de elasticidades das argamassas ensaiadas é apresentada no gráfico 02 , em GPa.

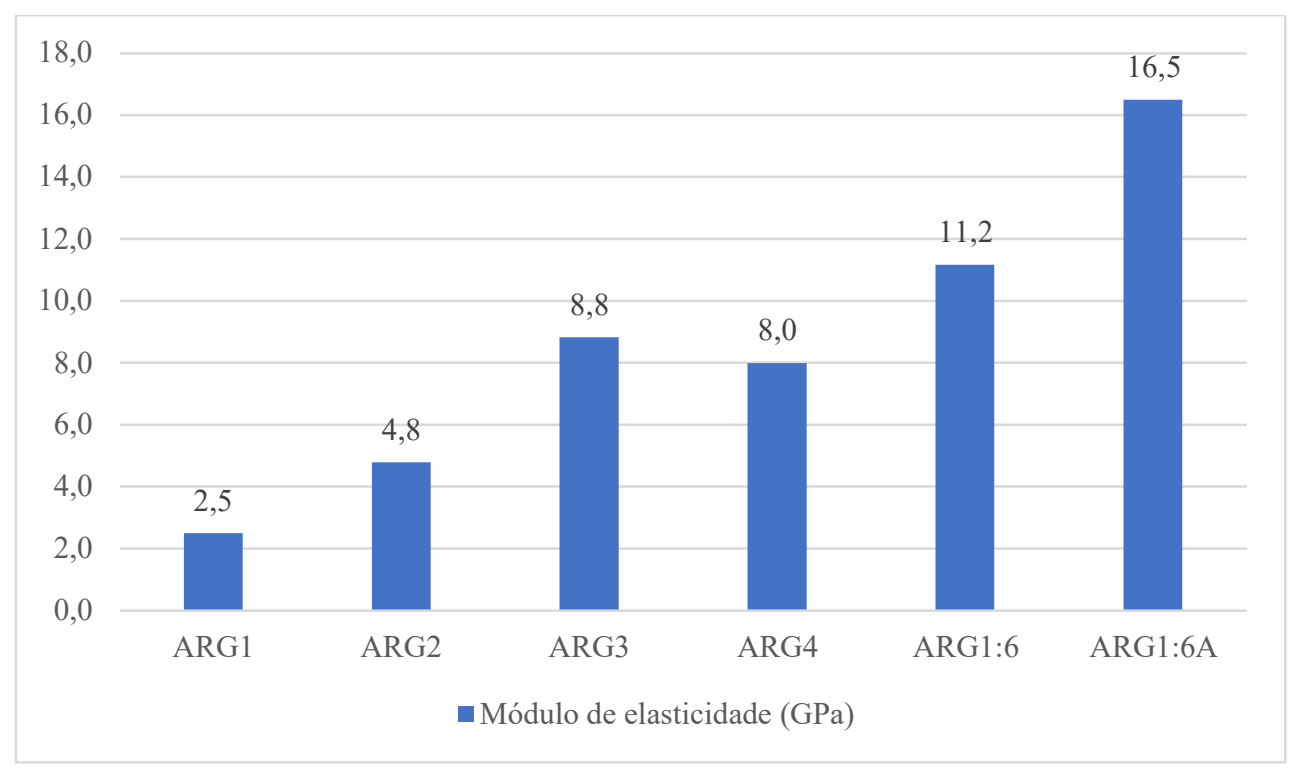

Gráfico 02: Médias dos módulos de elasticidades das argamassas ensaiadas (Fonte: Autor)

Nota-se que existe uma relação entre modulo de elasticidade e resistências das argamassas ensaiadas, quanto maior for o módulo, maior serão suas resistências. 


\section{CONCLUSÃO}

Visto que profissionais na área da construção civil são os principais responsáveis pelos projetos e execução das obras, é importante o conhecimento do material a ser utilizado no processo do encunhamento, e de como deve ser executado. A NBR 8545:1984, norma vigente para execução de alvenaria sem função estrutural de tijolos e blocos cerâmicos, contêm soluções e procedimentos antigos que deveriam ser elaborados em uma nova norma, visando proporcionar metodologias executivas e adoção de materiais corretos às construções contemporâneas.

Aos resultados dos ensaios laboratoriais, baseado na biografia dos autores citados no trabalho, obras em que se utilizada o sistema construtivo em concreto armado e alvenaria de vedação com blocos cerâmicos, o que se espera para o emprego do encunhamento é uma argamassa com menor resistência e módulo de elasticidade a fim de ser uma argamassa mais deformável e não rígida. E também de acordo com a NBR 13281:2005 as argamassas classificadas como R1 e R2 possuem resistência à tração na flexões baixas e $\mathrm{P} 1$ e $\mathrm{P} 2$ possuem resistências à compressões baixas. Consequentemente tem menor modulo de elasticidade e pode ser classificado como material resiliente segundo Daldon (2008). Apenas as ARG1 e ARG2 atenderam os critérios sugeridos pelos autores, com baixas resistências e módulos de elasticidade.

Patologias na região do encunhamento podem vir a ocorrer por falhas no comportamento dos materiais, ou de processos executivos que deveriam ter sido estudados logo no início do projeto, racionalizando todo o processo. E por este motivo foi desenvolvido este estudo para que critérios básicos e técnicas ideais relacionados ao encunhamento possam ser elaboradas, visando minimizar as manifestações patológicas.

Portanto, devem ser utilizados parâmetros de execução, classificação do tipo de estrutura tendo controles como agregados, traço, com aditivo expansor ou sem, volume de água na mistura, direcionados para cada tipo de classificação da estrutura seguindo uma normativa, para que possa padronizar os processos, e assim minimizar as manifestações patológicas na região do encunhamento. Quanto maior a deformação das vigas/lajes sobre a alvenaria de vedação, mais flexível o encunhamento deverá ser.

\section{REFERENCIAS}

ADITIVO TIPO I - Vedacit - Aditivo expansor. Ficha técnica. Revisada em jun/2017.

ARGAMASSA TIPO I - Fida - Argamassa de encunhamento. Ficha Técnica Revisada em fev/2019.

ARGAMASSA TIPO II - Quartzolit - Argamassa de assentamento e encunhamento. Ficha Tecnica. Revisada em $\mathrm{abr} / 2017$.

ARGAMASSA TIPO III - Bautech - Argamassa de encunhamento. Ficha Técnica. Revisada em mar/2014.

ARGAMASSA TIPO IV - Votoran - Matrix 1201 Argamassa de assentamento de vedação e encunhamento. Ficha Técnica. Revisada em ago/2019.

ASSOCIAÇÃO BRASILEIRA DE NORMAS TECNICAS. NBR 5738: Concreto - Procedimento para moldagem e cura de corpos de prova. Rio de janeiro, 2015.

ASSOCIAÇÃO BRASILEIRA DE NORMAS TECNICAS. NBR 8522: Concreto - Determinação dos módulos estáticos de elasticidade e de deformação à compressão. Rio de janeiro, 2017.

ASSOCIAÇÃO BRASILEIRA DE NORMAS TECNICAS. NBR 8545: Execução de alvenaria sem função estrutural de tijolos e blocos cerâmicos, 1984.

ASSOCIAÇÃO BRASILEIRA DE NORMAS TECNICAS. NBR 6118: Projeto de estruturas de concreto - Procedimento. Rio de janeiro, 2014.

ASSOCIAÇÃO BRASILEIRA DE NORMAS TECNICAS. NBR 13276: Argamassa para assentamento e revestimento de paredes e tetos - Determinação do índice de consistência. Rio de janeiro, 2016.

ASSOCIAÇÃO BRASILEIRA DE NORMAS TECNICAS. NBR 13279: Argamassa para assentamento e revestimento de paredes e tetos - Determinação da resistência à tração na flexão e à compressão. Rio de janeiro, 2005. 
ASSOCIAÇÃO BRASILEIRA DE NORMAS TECNICAS. NBR 13280: Argamassa para assentamento e revestimento de paredes e tetos - Determinação da densidade de massa aparente no estado endurecido. Rio de janeiro, 2005.

ASSOCIAÇÃO BRASILEIRA DE NORMAS TECNICAS. NBR 13281: Argamassa para assentamento e revestimento de paredes e tetos - Requisitos. Rio de janeiro, 2005.

ASSOCIAÇÃO BRASILEIRA DE NORMAS TECNICAS. NBR 16541: Argamassa para assentamento e revestimento de paredes e tetos - Preparo da mistura para a realização de ensaios. Rio de janeiro, 2016.

DALDON, Marcelo. Fatores que podem estar contribuindo para o aparecimento de manifestações patológicas na zona de encunhamento de paredes em obras de Porto Alegre. 2008. 89 f. TCC (Graduação) - Curso de Engenharia Civil, Universidade Federal do Rio Grande do Sul, Porto Alegre, 2008.

FRANCO, Luiz Sergio. Alvenaria - Revista Téchne. São Paulo. p. 56-57. Maio, 2004.

FRANÇA, Ricardo. Concreto: Deformações estruturais. Revista Téchne. São Paulo. p. 66-69. Dezembro, 2003.

LORDSLEEM JUNIOR, Alberto Casado. Execução e inspeção de alvenaria racionalizada. São Paulo: O Nome da Rosa, 2000.

PEREIRA, Manuel Fernando Paulo. Anomalias em paredes de alvenaria sem função estutural. Dissertação (Mestrado) - Curso de Engenharia Civil, Universidade do Minho, Guimaraes, 2005.

SANTOS, Marcus Daniel Friederich dos. Material de aula. Santa Cruz do Sul, 2019

SANTOS JUNIOR, Luís Viana dos. Projeto e execução de alvenarias: fiscalização e critérios de aceitação. São Paulo: Pini, 2014.

SILVA, R.C; GONÇALVES, M.O; ALVARENGA, R.C.S.S. Alvenaria racionalizada. Revista Téchne. São Paulo. Julho, 2006. Disponível em: <http://techne17.pini.com.br/engenharia-civil/112/artigo285542-1.aspx>. Acesso em: 02 mai. 2019.

THOMAZ, Ercio. Código de práticas n⿳0 01: alvenaria de vedação em blocos cerâmicos. São Paulo: IPT (Instituto de Pesquisas Tecnológicas do Estado de São Paulo), 2009.

THOMAZ, Ercio. Trincas em edifícios: causas, prevenção e recuperação. São Paulo: Editora Pini : Escola Politécnica da Universidade de São Paulo: Instituto de Pesquisas Tecnológicas, 2003. 